\title{
Feasibility Study of Boreholes Hand Drilling in Senegal -Identification of Potentially Favorable Areas
}

\author{
Cheikh Hamidou Kane ${ }^{1}$, Fabio Fussi ${ }^{2}$, Moustapha Diène ${ }^{3}$, Déthie Sarr ${ }^{1}$ \\ ${ }^{1}$ Laboratory of Mechanics and Modeling-Sciences of Engineering, University of Thies, Thies, Senegal \\ ${ }^{2}$ International Consultant, University of Milano Bicocca, Milano, Italie \\ ${ }^{3}$ Department of Geology, FST-UCAD, University Cheikh Anta Diop of Dakar, Dakar, Senegal \\ Email: cheikh.kane@univ-thies.sn
}

Received August 3, 2013; revised September 6, 2013; accepted October 4, 2013

Copyright (c) 2013 Cheikh Hamidou Kane et al. This is an open access article distributed under the Creative Commons Attribution License, which permits unrestricted use, distribution, and reproduction in any medium, provided the original work is properly cited.

\begin{abstract}
Drilling techniques commonly used in Africa are rather well suited for areas where geologic formations are hard and groundwater is not located at higher depths. Thus, for a large number of people living in rural areas, access to improved drinking water sources is often limited, due to the high cost of drilled boreholes that is closely linked to geographical, geological and hydrogeological factors. The analysis of various contexts has revealed that, in order to improve access to safe drinking water for underserved communities and populations, it is possible to consider less costly alternative solutions, compared to current options for water supply which are still expensive. In this paper, a simplified drilling technology at a very low cost has been demonstrated: "the manual or hand drilling", which is a practical solution for less than 40-m deep water points in alluvial terrains or low resistance rock formations. The feasibility study of manual drilling in Senegal has revealed that, even if it is not practical in all geological formations of the country, manual drilling remains an alternative solution for reducing costs and improving accessibility to drinking water in several areas in Senegal, particularly in the Senegal River Valley, along the northern coast, in Fatick and Casamance coastal zones. This study was used to set up map of areas suitable for manual drilling boreholes; it aims to strengthen the local private sector capacity to meet growing drinking water needs in rural areas.
\end{abstract}

Keywords: Manual Drilling; Rock; Resistance; Boreholes; Depth

\section{Introduction}

Manual drilling borehole technique is a practical solution for less than $\mathbf{4 0}$ meters deep water points in alluvial soils and low resistance ground. Although it is not a practical solution in all geological formations, there are many areas in Africa where it can effectively provide drinking water at a very limited cost in rural areas. This is especially true in small isolated communities that will never benefit from major drinking water projects because they are not generally taken into account in national water policy. The objective of this paper is to identify suitable areas for manual drilling use in Senegal. This study was carried out in collaboration with UNICEF-Senegal, as part of a project to support the dissemination of manual drilling techniques in Africa. To set up this study, we first had to collect local information (at the major institutions in charge with water database) and then transfer it to UNICEF ftp site. These data were processed in collaboration with a group of UNICEF contracted international consultants in USA; they helped compile them in a geographic information system (GIS). GIS tools use makes it possible to analyze different thematic layers which have contributed to identifying, in each zone, the parameters that help define manual drilling feasibility.

\section{Context}

The Senegal Manually drilled boreholes are not commonly developed or popularized in Senegal. These drilling techniques have started to be developed in Francophone Africa in the late 80s and have never been promoted at wider scale. In Senegal, the technique of manual drilling is rudimentary and is used only in sandy areas (lithology without clay and hard rock). It involves a uniform-diameter hand-auger penetrating the ground at a depth not exceed 20 meters. The material used for casing is PVC and the screen slots are made manually and 
wrapped in a cloth $(2 \mathrm{~cm}$ diameter slots in the PVC casing). In addition, the slotted party is not equipped with gravel pack, and wells are not usually developed. We also note that these boreholes are not often subjected to chemical analysis drilling acomplished. These manually drilled wells are often very common in the Niayes areas, in Casamance and exceptionally in Tambacounda (sedimentary ground at the alluvial zone, or in depression areas). In some terrains, although the water table is not deep, it is reached after penetrating clayey, lateritic, calcareous or marly layers. These shallow drilled wells (not exceeding 20 meters) tap water table aquifer and usually there are no lithostratigraphic data available after implementation, since these works most often carried out without permit. The unit cost of these wells ranges from 350,000 to 400,000 FCFA depending on the complexity of the ground and penetrated geologic formations; the investigation depths do not exceed in major cases 20 meters [1].

\section{Methodology to Define Suitable Areas}

\subsection{Criteria for Identifying Suitable Areas}

Two main parameters were used to define each area potential level throughout the country and then to identify of favourable areas:

\subsubsection{The Geological/Geomorphologic Ability}

This involves identifying areas where subsurface layers show hardness and permeability characteristics suitable for manual drilled wells implementation; it is about the possibility to manually perform a small diameter shallow borehole in permeable ground that could yield a significant flow rate.

\subsubsection{The Ability Based on Groundwater Depth}

This consists of identifying areas where you can find exploitable flowing groundwater at a depth compatible with manual drilling techniques. In Senegal, it might not be useful to set up a morphological classification based on the elevation model, to identify morphologically favourable areas; the following reasons can be evocated:

- The ground morphology is almost flat and then automatic process creating different morphological areas does not give acceptable results;

- The occurrence of favourable superficial deposits (not mentioned in the geological maps) is already taken into account in available morpho-pedological map.

In addition, areas located in Eastern Senegal, where relatively high differences in altitudes are occurring, are considered in our analysis. We do consider as well the presence of weathered layers that thickness varies locally with respect to topography. These aspects are not well documented in morphologic and soil maps.

\subsubsection{Determination of the Geological Suitability}

This mainly consists of identifying areas with subsurface layers characterized by hardness and permeability suitable for hand drilled boreholes. These terrains are made of primary geological layers or weathered/sedimentary formations underlain by the main geological formation.

\subsection{Information Used}

Main information sources used in this study are listed below [2]:

- Senegal aquifers map, published by the Water Management and Planning Department in 2008, available in soft copy (Figure 1);

- Morphological and soil map (Figure 2);

- Water points database (dug wells and boreholes);

- Stratigraphic data of boreholes logs.

Upon the moment we completed the study, the electronic version of Senegal geological map was not available. Consequently we have used aquifers map to characterize general geologic features, in addition we integrate information provided by morphologic and soils maps.

\subsection{Definition of the Geographical Unit to Be Analysed}

Based on observation and crossed-cutting analysis of different information levels, the study found that aquifers units mentioned on the map are generally overlain by thick geologic layers generated by sedimentation or weathering process. Thus, hardness and permeability characteristics of the main aquifer recorded on the map, do not match in most situations with the lithology currently existing in the first 30 - 40 meters (interesting fringe for manually drilled borehole). We do notice that on the same aquifer unit, subsurface layers features are very different.

At the other hand units recorded on the morphological and soil map are more in line with the current subsurface layers features; however they may show various characteristics depending on geological formations they belong to.

To identify potential areas that are characterized by the same type of subsurface layers, we have used a combination of aquifer units (Figure 1) and morphopedological units (Figure 2) as a criterion for defining geometric basis for the geological suitability classification. The two combined units are thus considered as two information layers (aquifers and morphopedology), which produced a vector layer where each polygon is characterized by a specific combination of morpho-pedological units and aquifer. 


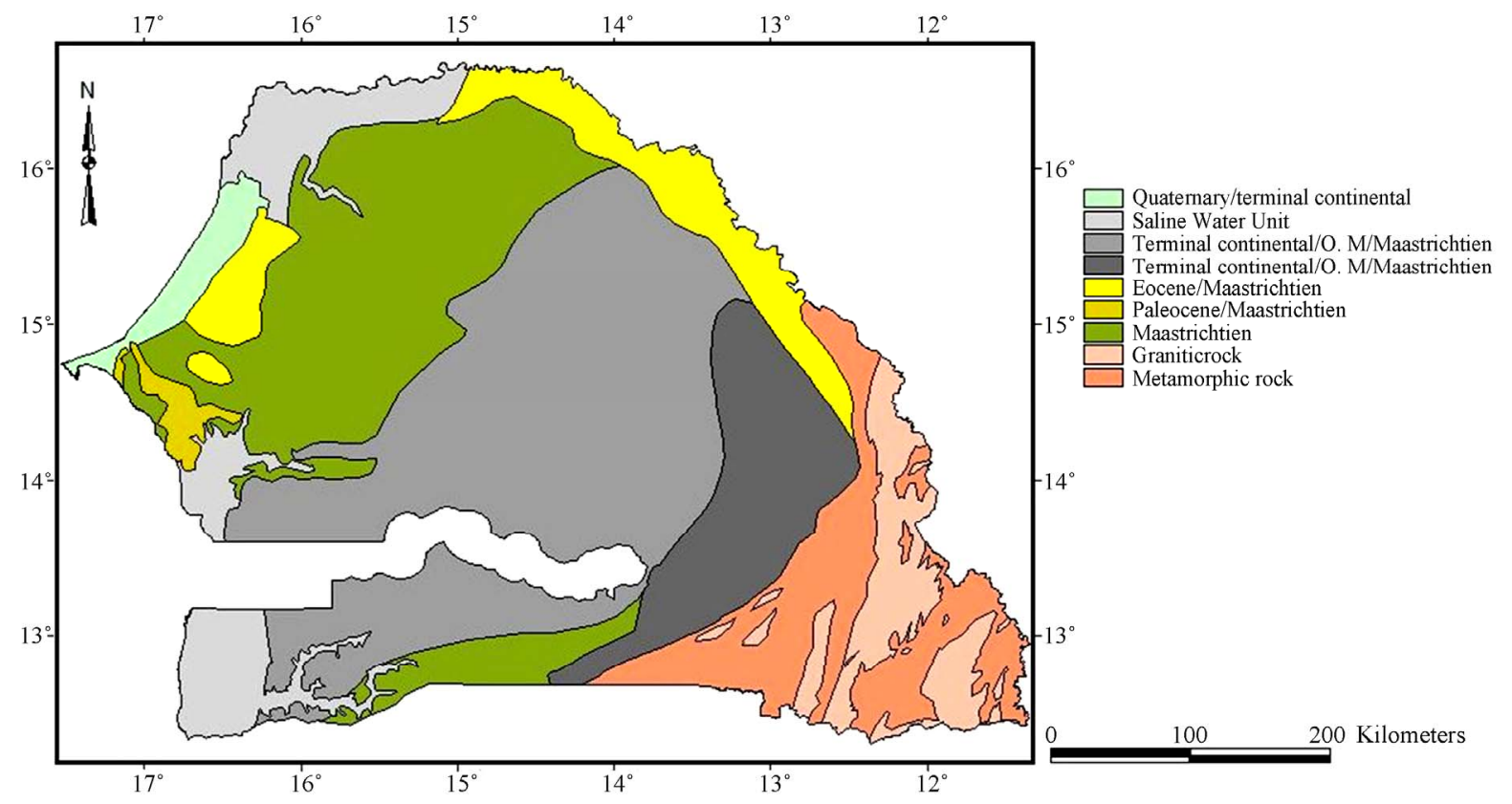

Figure 1. Senegal aquifers map (source: Water Resources Management and Planning Department).

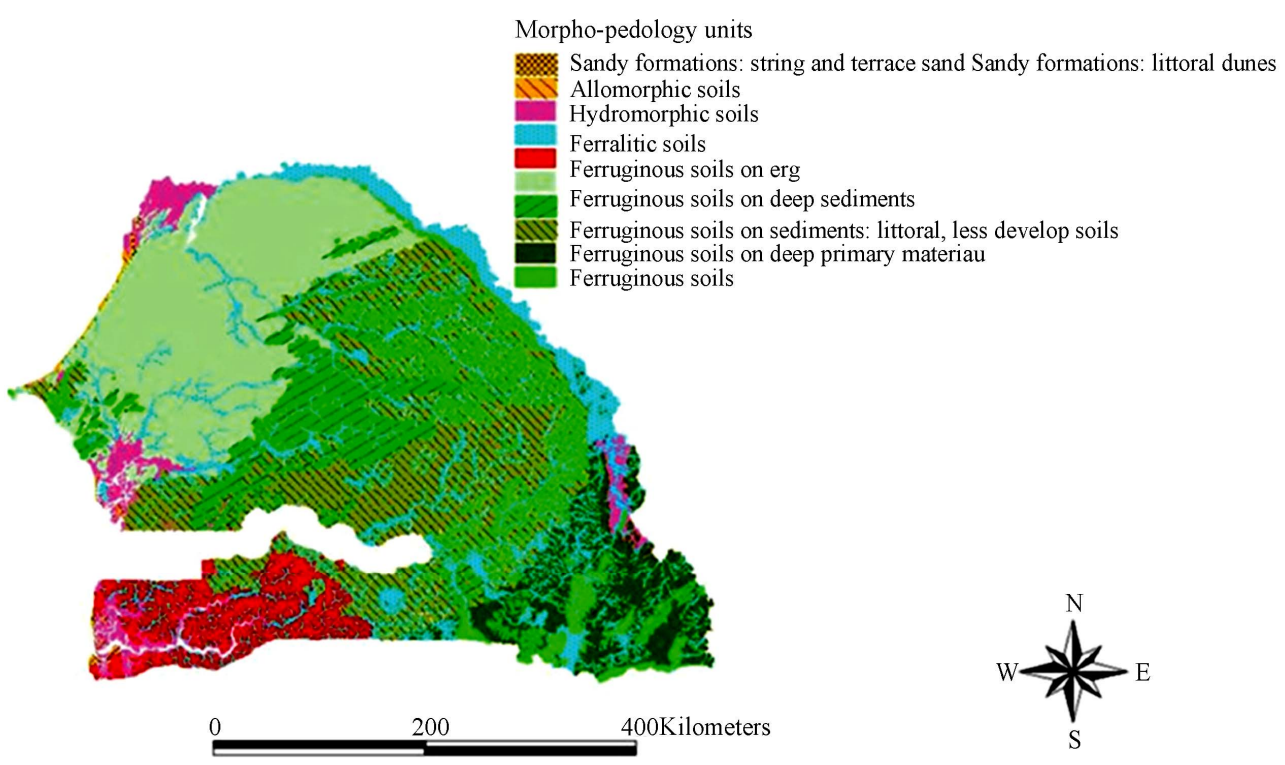

Figure 2. Morphologic and soils map.

\subsection{Assessment of Subsurface Layers Characteristics}

For each unit (morphopedological +aquifer) we have considered:

- Lithology and texture of the most superficial layers derived from boreholes logs (considering only layers which thickness exceeds 5 meters);

- The thickness and depth of all lithological units, lightly or meanly consolidated (hardness);

- The spatial occurrence of boreholes penetrating lateritic levels and their percentage (Figure 3);
- The presence of manual wells, and their relationship with existing boreholes (Figure 4).

Drilling log data (Figure 3) were used to assess depth of low resistance geologic layers with regard to their hardness characteristic and laterite occurrence as well. Data processing has showed that almost all borehole logs throughout the country encounter low resistant geologic layers, within the first 50 meters, which might be penetrated manually. In other words, there are favorable conditions for manual drilling, in terms of subsurface layers hardness. At the same time it is obvious that, at the central and southern parts of the country interbedded lateritic 


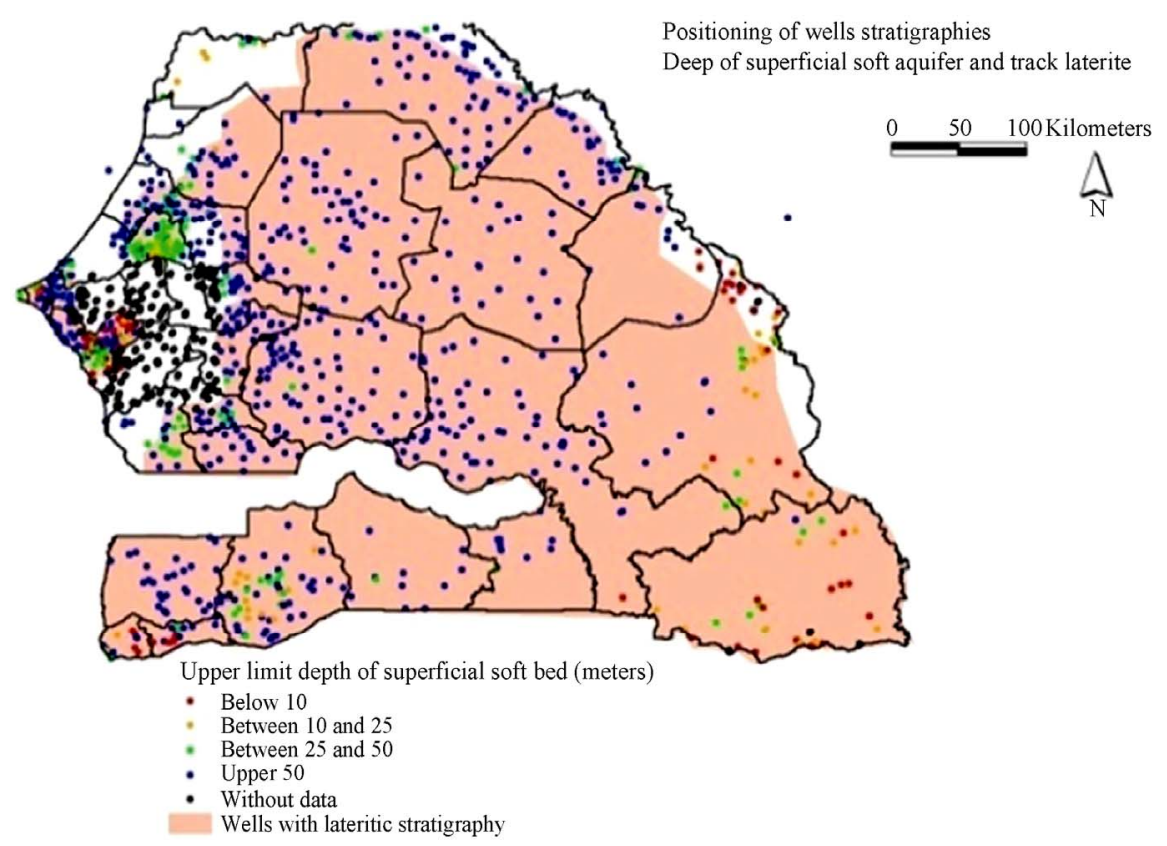

Figure 3. Subsurface layers characteristics derived from available boreholes logs.

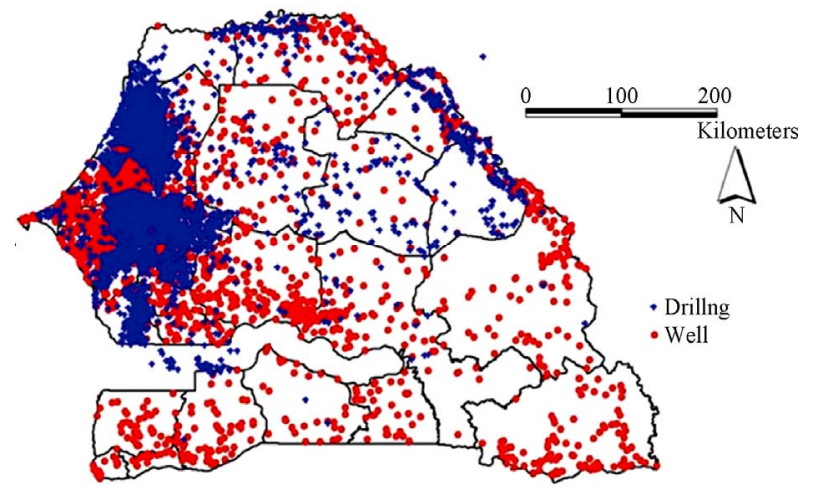

Figure 4. Dug wells and boreholes distribution map.

layers with 3 - 5 meters thickness are commonly found in borehole logs. In other words, if the lateritic layers can not be considered as an obstacle to manual drilling, it is more adequate to adopt (in major country parts) appropriate techniques suitable for penetrating through a few meters lateritic layers.

From the observations results we came out to an assessment of subsurface layers characteristics (such as average features up to 30 meters depth) for each aquifer unit (morphopedological +aquifer). The following aspects have been defined:

- A description of probable lithology subsurface;

- Estimated subsurface layers hardness;

- The subsurface layers permeability;

- The geological suitability class.

\subsection{Allocation of Geological Suitability Classes}

Based on subsurface layers characteristics, a geological suitability value was assigned to each area. The following classes are considered in geological suitability classification (Figure 5):

FO: High geological aptitude area that corresponds to very favorable conditions of hardness and permeability on the main aquifer formation;

FO-alt: High geological aptitude area of weathered layer composing the main aquifer formation;

FOR-dep: high geological aptitude area of sedimentation deposits composing the main aquifer (deposits are generally consistent with the morpho-pedological description);

MO: average geological aptitude of layers with hardness features that correspond to moderately suitable aquifer rock;

MO-alt: average geological aptitude area of sedimentation deposits composing the main aquifer (deposits are generally consistent with the morpho-pedological description);

FA: Poor geological aptitude area, corresponding to hydrogeological environment that is generally not suitable for manual drilling.

\section{Results Analysis Methodology}

\subsection{Suitability Determination Based on Geological Features}

We can observe that the country's major part shows geological environments with average aptitude for manual drilling. Geologically, the Senegal River Valley area [3], the Niayes zone of Northern Senegal [4], and coastal area of Southern Senegal are considered as very suitable. 


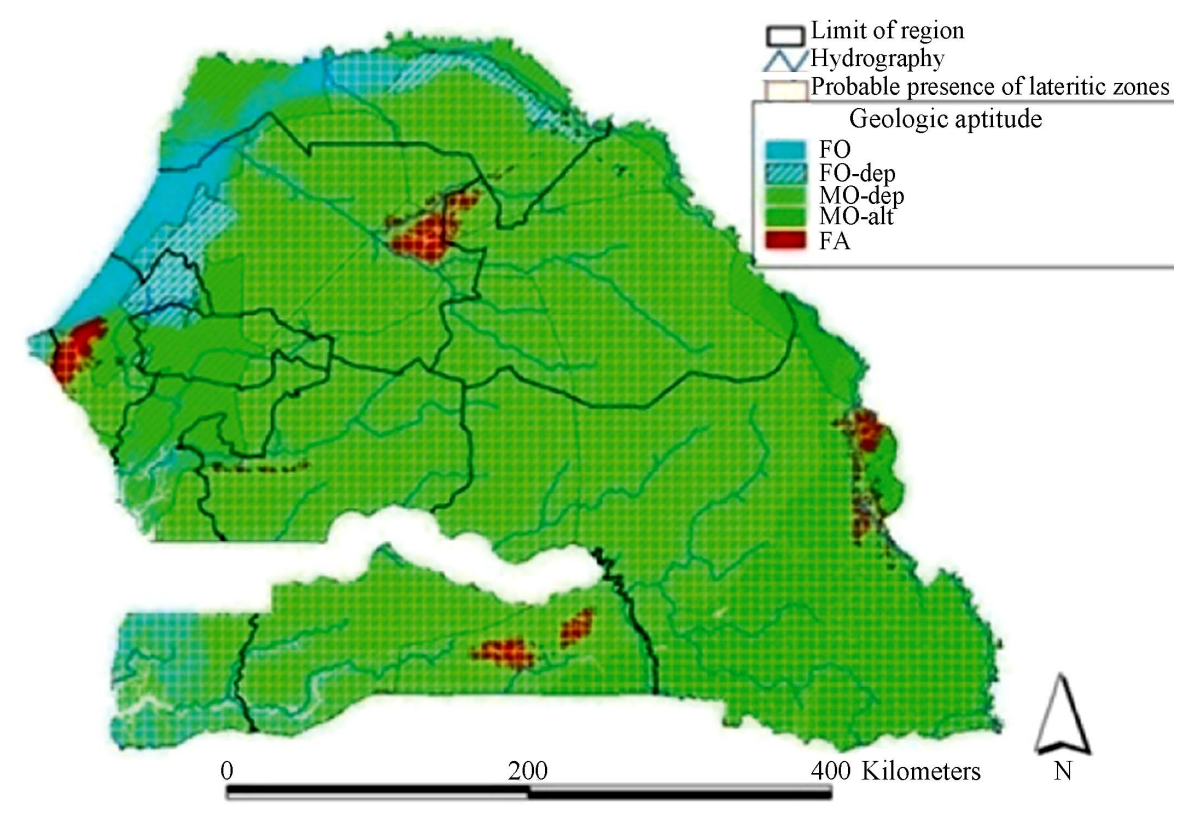

Figure 5. Map of geological aptitude to manual drilling.

Other less important areas show high geological limitations and are considered as areas not favorable for manual drilling.

In the South-East country part, the geologic aptitude is considered as average due to weathered formations occurrence; in that area, we have crystalline basement, hard consolidated rocks that may become partially favorable with respect to weathered shallow layers occurrence. Therefore, the feasibility of manually drilled wells will depend either on weathered deposits accumulation related to depression (or low slope), or on rocks permeability (crystalline rocks, especially the fine-textured rocks produce weathered layers with clay presence). It should be noted that throughout the central area there are lateritic layers. If those layers are usually perforated with manual techniques (when thickness is thin) it must be accepted that percussion techniques are the most appropriate ones.

\subsection{Suitability Determination Based on Water Table Depth}

In Senegal, there is database containing information over 7000 recorded water points (wells and boreholes), particularly in the western and northern area (Figure 6). These data can provide relevant information to assess water table depth. However, in the central and the eastern part of the country, the quality of information is poor. In order to assess manual drilling suitability with respect to water table depth, we have considered directly average water table depth provided by the available groundwater depth map.

The following aspects have been taken into account:
- The water points' density is very different from one area to another, and in some of them the distance between recorded water points is long. Therefore, in order to get reliable results, the interpolation algorithms require reference data' distribution to be as homogeneous as possible and compatible with the size of interpolation mesh;

The local water depth variations depends on groundwater piezometric level' shape, as well as local topographic variations, which values are not recorded in water points database (Records consider water table depth, but not absolute static level in terms of elevation above sea level).

The following categories/classes were used to estimate suitability based on water table depth (Figure 7):

- Water table depth under $10 \mathrm{~m}$ : compatible with different manual drilling techniques, suitable;

- Water table depth between 10 to 25 m: manual drilling is possible. For this category all the drilling techniques are applicable, however manual drilling will require more consideration to resistant layers occurrence that may prevent to reach expected depths;

- Water table depth beyond $25 \mathrm{~m}$ : generally manual drilling techniques do not match with these depths.

We can notice hat along the coast, in Casamance area as well as the eastern part of the country, manual drilling is possible if we refer to water table depth. On the other hand, manual drilling techniques use is very difficult, in the central part of the country, because groundwater depths are generally high. The information available for establishing water table map is insufficient. Consequently, the assessment was carried out with limited water points' number, which shows out huge differences in 


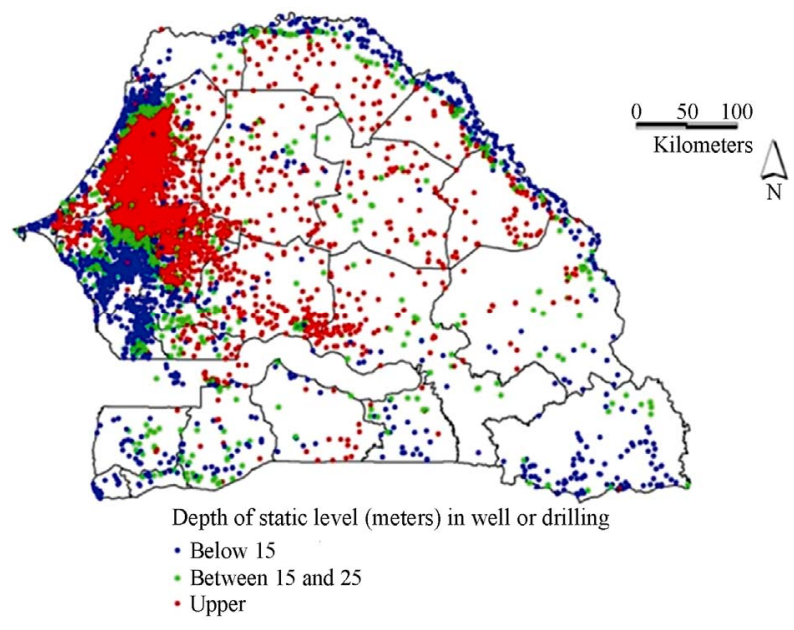

Figure 6. Map of water table depth.

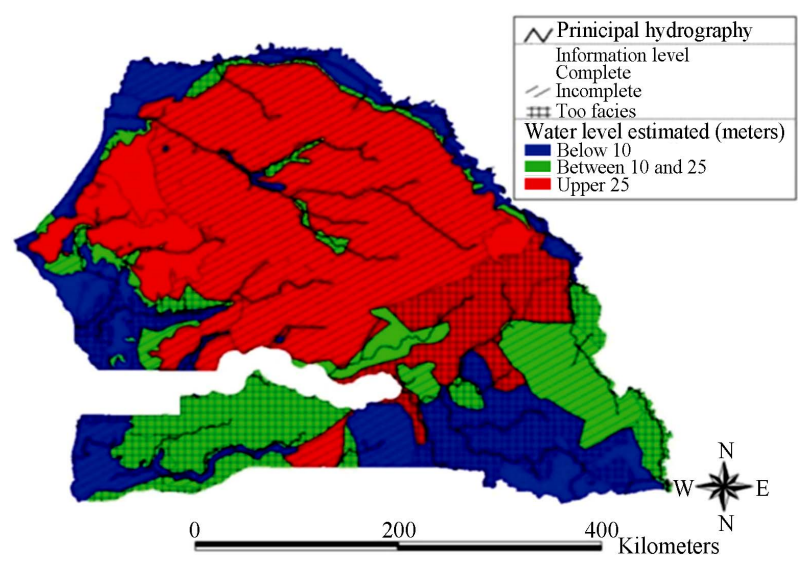

Figure 7. Map of assessed water table depth.

water static levels. In this context, the general trend of water level distribution does not clearly emerge. Therefore, more detailed analysis requires complementary information along with field observations that provide accurate indication on shallow groundwater depth in targeted areas.

\section{Total Suitability Determination}

The final assessment of suitability for manual drilling techniques in Senegal was done based on cross-cutting information provided both by geological suitability and aptitude related to water table depth.

The following suitability classes were defined with regard to geological features and groundwater depth as well (Figure 8):

- Very favorable: refer to areas where geological formations features and water table levels are both favorable;

- Favorable: refer to areas where, one parameter shows an average aptitude for manual drilling use, and on the other is rather favorable;

- Little-favorable: refer to areas where both parame- ters show an average aptitude (i.e. favorable with some limitations); in these areas manual drilling techniques may be used depending on topographic conditions, however in general these areas have constraints for implementing these techniques. For instance in the eastern part of the country, undulating topography (with low altitude zones) and weathered layers occurrence may provide specific environment for manually drilling techniques' use.

- Not favorable: refer to areas where, either one or both parameters have suggested unfavorable conditions for manual drilling; therefore these techniques are generally difficult to use.

\section{Results}

\subsection{The Country Central Area}

This area is considered not suitable for manual drilling mainly because of water table level, which is relatively deep [5]. At the western, southern and northern parts (Senegal River valley) encounter very favorable areas for manual drilling techniques' use; these are listed below:

\subsection{The Valley Area and along Senegal River}

This zone consists of a $10-25 \mathrm{~km}$ strip along the Senegal River starting from Bakel to the River mouth. It is part of administrative regions of Saint-Louis, Matam and Tambacounda. That eco-geographical area lays between two climatic zones: the Sahelian from Northwest to Northeast, and Sudanian domain in southeast. In the Sahelian zone the mean annual rainfall is $200-300 \mathrm{~mm}$; this area is subject to pluviometric deficit and irregular rainy season, irregularity with relevant interannual variations. In the Sudanian zone rainfall is about $500 \mathrm{~mm} /$ year.

Based on the information from morpho-pedological map and boreholes logs as well, the subsurface layers are supposed to be made of unconsolidated sediments characterized by various permeability (clay, sandy clay, or alternatively sand). The geological formations' features show that it is possible to set up manual drilling in these areas; however, low production yield may be the main constraint.

\subsection{The Northern Coastal Area}

It extends along the coastal strip north of Senegal and covers the administrative regions of Dakar, Thies, Louga and St Louis. The area is characterized by Quaternary sedimentary formations that overlay older Secondary and Tertiary geological formations (Maastrichtian, Paleocene and Eocene). These Quaternary layers extend to major country part and are made of sandy material.

The available and accessible water resources supplying people including farmers are mainly from two sources: 


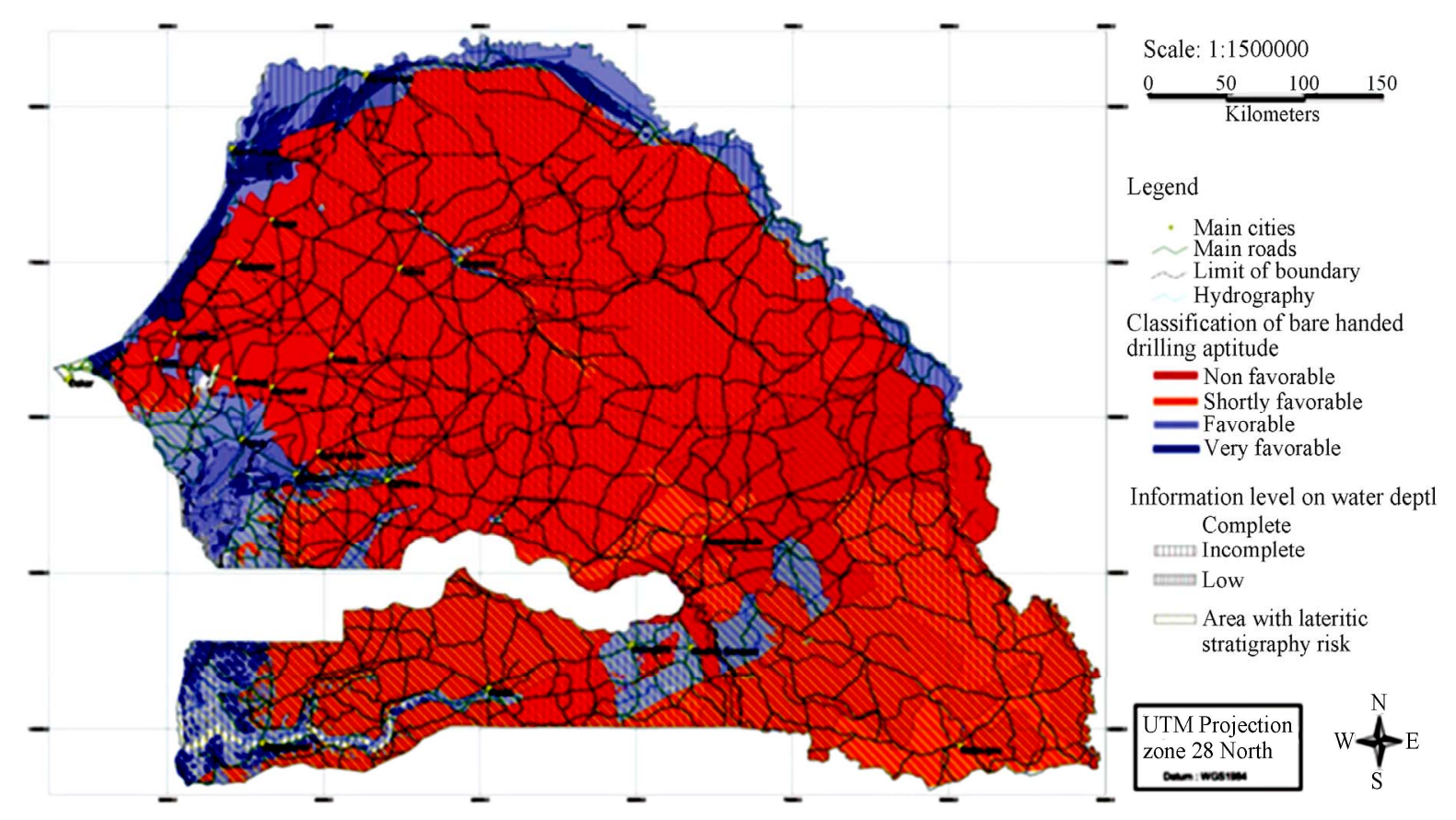

Figure 8. Map of areas suitable for manual drilling.

groundwater and surface water; the latter consists of local lakes and ponds at reduced number, which usually constitute main outlets of rivers system active only in rainy season $[4,6]$.

If we refer to geological features and water table depth, this area is considered to be the most favorable one to manual drilling. It is necessary to pay attention, locally in some areas, to saline intrusion risk. Consequently, it is appropriate in this case to develop a water supply strategy using hand pump technologies. This strategy is suitable for small rural communities, which water demand is limited; by this way saline intrusion risk can reduce in this coastal aquifer. The resulting yield of manually drilled water points can easily meet water supply demand in these areas.

\subsection{The Coastal Zone in Fatick Region}

In this area, groundwater is not very deep and occurring subsurface layers are made of sandy clay and sand sediments. It is considered as favorable zone, with limited borehole yield, particularly in ground bearing clay in the consolidated deposits.

\subsection{Casamance Zone}

In this area, the geological conditions are generally favorable, they consist of sandy clay or clay layers. From the perspective of groundwater level, shallow water depth areas are identified in the western part (Ziguinchor administrative region), whereas areas with relatively deep water table are located in the central part (Kolda region).
That delimitation implies considering Casamance west part as favorable to hand drilled wells. In reverse its central part is partially favorable, since drilling depth may be beyond $20 \mathrm{~m}$, and in addition interbedded more consolidated layers may be found there. In this context, more appropriate drilling techniques must be used (lateritic layers).

\section{Conclusion}

The design and construction of hand drilled wells using appears to be a practical solution for water points tapping shallow groundwater (40 $\mathrm{m}$ deep) occurring in alluvial soils or slightly consolidated formations. Even though it is not a suitable solution in all geological formations, this study has identified favorable areas in Senegal where this technique can be applied to provide drinking water for rural populations at a very limited cost. In Senegal (Casamance), a manually drilled well fitted with hand-pump costs approximately USD 3300, including bore-hole/ well, pump, superstructure and supervision. At the other hand, percussion drilled borehole with the same equipment costs USD 14,300 in Kedougou, and a 30-m deep dug well fitted with the same surface equipment costs more than USD 16,000 .

\section{REFERENCES}

[1] C. H. Kane, "Etude sur l'optimisation du coût des Forages en Afrique de l'Ouest-Rapport Sénégal, Financement Banque Mondiale,” 2007.

[2] PAGIRE, "Plan d'Action pour une Gestion Intégrée des 
Ressources en Eau, Rapport Sénégal, DGPRE,” 2007.

[3] M. Audibert, "Delta du Fleuve Sénégal Etude Hydrogéologique Projet Hydroagricole du Bassin du Fleuve Sénégal," 1970.

[4] SENAGROSOL/EDE, "Etude d'impact environnemental et sociale des travaux de mobilisation des ressources alternatives pour l'irrigation des Niayes,” 2009.
[5] PSE/COWI/POLYCONSULT, "Etude Hydrogéologique de la Nappe Profonde du Maastrichtien.”

[6] SENAGROSOL, "Evaluation Environnementale Stratégique (EES) des activités relatives à la promotion de la micro irrigation dans les Niayes, le Bassin Arachidier élargi a la région de Tambacounda et à la Casamance,” 2009. 